\title{
IDENTIFYING ELEMENTS OF ENTERPRISE WIDE APPLICATION SELECTION ECO-SYSTEM
}

\author{
Mirosław J. Skibniewski \\ A.J. Clark Chair Professor, Dept. of Civil \& \\ Environmental Engineering, \\ University of Maryland, College Park., USA \\ mirek@umd.edu
}

\author{
S. Ghosh \\ $\mathrm{PhD}$ Candidate in Project Management, Dept. of \\ Civil \& Environmental Engineering, \\ University of Maryland, College Park, USA \\ sghosh12@umd.edu
}

\begin{abstract}
Technology acceptance is a challenge that can be addressed properly if decision makers of technology acceptance are aware of all issues that need to be addressed. Borrowing theory of basic ecology, researchers propose an information technology (IT) ecosystem (IECOS) and identified in the entirety all the elements present at IECOS. The study focuses on identified elements of IECOS borrowing theory of technology acceptance model (TAM). A simplified version of technology selection is presented to guide prospective enablers to select a new enterprise wide application.
\end{abstract}

\section{KEYWORDS}

Ecology, technology acceptance model, compatibility, usefulness

\section{INTRODUCTION}

Mankins and Steele (2005) pointed out that to ensure good performance in a company, it is required to use a rigorous framework and use common business processes during any system implementation. As interest increases in creating sustainable solutions to information technology (IT) solutions, the need for methods to understand and predict the outcomes of strategic decisions becomes more urgent.

Existing literature provide case studies and examples how to maximize the use of packaged application systems (Drayer and Wight, 2002). To better understand and predict key outcomes associated with technology acceptance, several theoretical models have been proposed (for a recent review, see
Venatesh et al. 2003) which are based on conceptual understand of technology acceptance. Technology acceptance model (TAM) (Davis, 1989) is one of the most robust models proposed and several authors have extended TAM from different perspective. Several authors extending the theory of acceptance based on beliefs (Karahanna et al. 2006), likelihood on acceptance (Bhattacharya and Sanford, 2006) are the recent extensions. Several authors have extended TAM into a specific aspect of technology acceptance, e.g. in the context of training (Sharma and Yetton, 2007).

Recent studies tried to incorporate perceived compatibility and therefore either the studies have incorporated multiple variables (e.g. 21 as in this context) which becomes simple impossible to 
measure. The other option was to keep the model simple, and therefore missing a specific set of components missing from the study, leading to an incomplete study. However several studies are reported to specific type of application and framework of evaluating such choices (Luo and Strong, 2004). These studies are focused to explore issues related to such applications, e.g. for ERP, business process reengineering is reported as one of the biggest challenges (Robey et. al. 2002; Hammer, 1999).

Abundance of disintegrated information and its timesensitiveness while implementing IT solutions makes it a complex process to manage. Consulting companies accumulated implementation experience with different IT implementations systems, many consulting companies are representing implementation methodologies to standardize implementation process. However these methodologies are primarily designed after a vendor is selected for implementation and therefore does not help organization willing to implement the new solution. Also as application solution industry matures, major solution vendors have attempted to tailor their standard systems software to the needs of specific market segments. There are no methodologies available in the market place to either from consulting companies nor professional association based methodologies. This paper is an attempt to develop a unified framework. Information provides an understanding of the current application space, both internal and external. Researchers and executives therefore started to appreciate information as a tool, spending millions of dollars in systems installation and upgrades, to automate back offices and extending its system footprint. Companies attempted to snatch data in every conceivable way within existing business processes.

\section{LITERATURE REVIEW}

There were several attempts made in the past to structure the application acceptance process inclusive of task structuredness (Celderman, 1997). Although different management support system may support unstructured and semi-structured tasks (Ariav and Ginzberg, 1985; Hogue and Watson, 1985; Pearson and Shim, 1994) However from a practical perspective, the challenge is in the unknown domain of reference and therefore inability to define task structuredness. Tiwana and Mclean (2005) addressed the issue of how individually held expertise

In information systems development (ISD) teams results in creativity at the team level during the development process.

There are also several extensions TAM in special situations, e.g. enterprise resource planning (ERP) implementation environment (Amoako-Gyampah and Salam, 2004) and wireless internet ( $\mathrm{Lu}$ at al. 2003, $\mathrm{Wu}$, SC Wang, 2005). However TAM has been extended to simple an unmanageable number of variables (Somers and Nelson, 2004).

The technology adoption research domain has yielded a number of valid predictors of adoption, yet the under-utilization of information systems continues to plague organizations. The primary goal of this research effort is to identify individual and structural variables that may strengthen the predictive validity of tradition technology adoption frameworks. The significance of the research is derived from the fact that minimizing the waste of time and resources on technologies that are fleeting and developing strategies that effectively address the underutilization of technologies continue to be key challenges for organizations. The proposed research contributes to existing knowledge by (1) identifying a core set of predictor variables that may strengthen the predictive validity of traditional adoption frameworks and (2) presenting a comprehensive model of adoption that is theoretically grounded in the quantitative and qualitative literature as a means to gain better insight into the role of individual and structural influences on the adoption decision (Jackson, 2006). A new paradigm is also proposed to address short coming on TAM (Bagazzi, 2007)

\section{CONSTRUCT OF ECOSYSTEM}

Ecology (from Greek: oíkos, oikos, "household"; and $\lambda$ ó $o s$, logos, "knowledge") is the scientific study of the distribution and abundance of living organisms and the interactions among organisms and between organisms and their environment. The environment of an organism includes both physical properties, which can be described as the sum of local biotic factors such as insulations (sunlight), climate, and geology, and biotic factors, which are other 
organisms that share its habitat. The word "ecology" is often used more loosely in such terms as social ecology and deep ecology and in common parlance as a synonym for the natural environment or environmentalism (wikipidie.com).

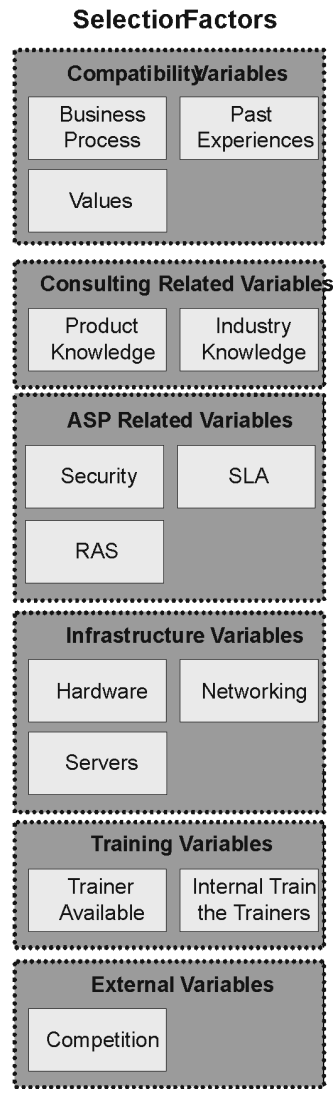

Figure 1. Proposed IECOS

The first principle of ecology is that each living organism has an ongoing and continual relationship with every other element that makes up its environment. An ecosystem can be defined as any situation where there is interaction between organisms and their environment.

The ecosystem is of two entities, "the entirety of life" or biocoenosis, and the medium that life exists in or biotope. Within the ecosystem, species are connected by food chains or food webs. The concept of an ecosystem can apply to units of variable size, such as a pond, a field, or a piece of dead wood. An ecosystem within another ecosystem is called a micro ecosystem. For example, an ecosystem can be a stone and all the life under it. An ecosystem could be a forest, and a macro ecosystem a whole eco region, with its drainage basin.

The main questions when studying an ecosystem are:

- Investigation the ecosystem's dynamics and changes

- The methods of which an ecosystem interacts at local, regional and global scale

- Whether the current state is stable

- Investigating the value of an ecosystem and the ways and means that interaction of ecological systems provides benefits to humans, especially in the provision of healthy water.

\subsection{Definition of IECOS and its components:}

In ecology, an ecosystem is a combination of all elements of an area. Ecosystems are the smallest level of organization in nature that incorporates both living and nonliving factors. We define an Information Technology Ecosystem (IECOS) is a combination of all factors that influence directly and indirectly influence adoption of a new technology. IECOS consists on an implemented IT system, executive sponsors, and users, developers of the application to be adopted, software and business process support, implementers and trainers of that eco-system. In the following section each of the components of the IECOS will be explored (see Figure 1).

IECOS: Borrowing the theory from basic ecology, we define, itcoenosis, as the entirety of all information technology elements in the application implementation process.

We define 'Itope' as the medium of all enterprise applications.

We develop our identification of components based on expert (experts are identified to have multiple full life cycle implementation experiences in multiple countries) interviews and then with extensive literature review to understand the specifics of that component. Acknowledge that interaction between components of the eco-system is often dynamic in nature and components' role change over time. Therefore all components are captured in the stage 
when an organization is conceptualization stage to accept a new technology (Ghosh and Nagheban 2007). The frame of reference to identify components is based on knowledge networks in the organizations at learning network level (Back et al. 2005). The purpose of this research is to identify IECOS.

Cha and William R King (2005) identified application requirements into two components:

Resources: Hardware, Software, Human Resources and Integrated Managerial and Technical Capabilities and Functional Outputs: Systems Performance, Information Effectiveness and Service Performance. Clearly the study does not identify all the components required for an enterprise wide application implementation. Therefore to identify components of IECOS, a pilot was conducted with 16 enterprise application users, consultants and end users to identify all the elements considered as part of the implementation.

\subsection{Components of IECOS}

Hall and Day (1977) consider three uses of models: understanding, assessing, and optimizing. In this paper, an understanding model is developed which is assessed using data gathered from IT system enablers and based on the data and analysis performed on that data, the model is optimized.

\subsection{Belief components}

One of earliest definition and exploration of compatibility is defined as belief of using an innovation is perceived with the existing sociocultural values (Rogers, 1962). The definition of compatibility is later extended to include cognitive compatibility as what people are thinking and therefore perceive as useful (Torntzky and Klein, 1982). When an organization is willing to adopt a new technology, there are some prior beliefs that drive the selection procedure. The adoption of new technology is driven by prior knowledge of the key decision makers, their past experience, organization's existing technology basis, as well other collaterals like trade association journals, professional community meetings as well other information sources.

The extensive theoretical construct was developed based on theoretical definitions and empirical derived dimensions (Ramiller, 1994). Therefore, the tacit knowledge base exists in perceived believes in specific technology acceptance. In the learning organization explain what the criterion of learning organizations. However the tacit knowledge base of the IT adopters are required to fit innovation with adopter's existing values, previous experiences and current needs (Taylor and Todd, 1995). To develop proper infrastructure in place for the innovation of adopting a new application, practical compatibility and value of compatibility should be pre-existing (Harrington and Ruppel, 1999).

Karahanna et al (2006) identified the following four components:
a. Compatibility with preferred work style
b. Compatibility with existing work practices
c. Compatibility with prior experiences
d. Compatibilities with values of users towards use of technology

Kanahanna et al showed that b, c and d has direct impact on the perceived usefulness and perceived ease of use. Therefore for our study these three criterions are as the basis of considering perceived acceptance. We extended the belief component also to extend to perceived availability of functionalities (Chung, 2007) offered by a specific product or solution that is being implemented.

\subsection{Support components}

Successful innovation requires tracking your partners and potential adopters as closely as you track your own development process (Ron Adner, HBR). For any technology to be acceptable, sustainable and eventually to be called a successful implementation, proper support structure should be in place. Support components are identified into three components:

a. Perceived support from the internal support organization

b. Recruiting a consulting organization to support the implementation and may extending to provide post production support and thereby perceived usefulness

c. Perceived support from the product selected in the process 
Application service providers (ASPs) are third party service firms that deploy, manage and may also remotely host remotely located servers and application through a central location. Internal support organizations are the specialized division, department of group of individuals within the same organization who are entrusted to support the specific application. Several existing literature on ASP has identified the participants of the ASP model are identified as a) solution developer, b) customer, c) business service provider and d) platform enabler (Gurbaxani, 1996).

ASP support is also direct consequence of globalization and organizations are looking for metanational advantage (Doz et al.) However the coordination problem of technical, temporal or process oriented (Espinosa et al 2007). Software as a service is also a model that has gained recently growing interests in the market segment.

ASP support Ekanayaka et al. (2003):

- $\quad$ Security (Currie and Seltsikas, 2001)

○ Physical security

- Security of data and applications

- Backup and restore procedure

- Disaster recovery plan

- $\quad$ Ability to Integrate ( Greg, 2000 )

- Ability to share data between applications, automatically populating one application with data from another application

- $\quad$ Pricing ( Gerrit and Gunther, 2000)

- Effect of TCO

- Hidden costs/Charges

○ Return on investment

Cost is still a critical driver in selecting ASPs and proper cost benefit needs to be worked out.

- Customer Service

○ Help desk and training

○ Support for administration of accounts

- SLA Monitoring and Management

○ Clearing defined monitoring procedure
- Reliability, Availability and Scalability

○ $24 X 7$ supports.

\section{E: Infrastructure components:}

Ghosh and Ghosh (2003) proposed that executives need to have a complete understanding of the technical challenges involved in adopting a new enterprise wide system and proposed that the three elements to consider are, a) network upgrade, b) hardware upgrade and c) providing global support

Executives are required to judge each of the aspects separately and at the end match all the three to make the decision which ERP package to adopt. For current research, purely from infrastructure perspective, we consider network and hardware are considered and support is considered as a separate item.

\section{F: Training components:}

Also, there may be a compatibility with preexisting software development and compatibility Hardgrave et al. 2003), but none for packaged software. Several researchers identified that success of IT adoption may be greatly influenced by how closely an individual's personal values and perceived values of the organization overlap ( Cazier 2003, Cazier and Gill 2003, Cazier et al 2002).

IT enablers identified training to be a critical components (Sharma and Yetton, 2007) of ensure success, primarily in the packaged software market segment. Packaged software are conceptualized, developed and marketed by a vendor with out specific input from the implementing organization. Following Sharma and Yetton, the effect of training on implementation success is contingent on both technical complexity and task independence. The above mentioned theory therefore evaluated in practical purposes to ensure the key measures of success in training. Keeping it simple, cost was perceived to a critical component of training activity. Training costs organizations in two different way, losing immediate productivity and loss of value producing hours and cost of the training itself. Borrowing from Sharma and Yetton, IT adopters identified that depending on which stage of the project, some of the key end users or power users may be trained by external trainers with an expectation that these selected individuals would 
become solution champions in the organization and play a critical role in the project. These individuals would then act to train the other end users who are not power users.

\section{INDUSTRY DISCUSSIONS: PROJECT BASED INDUSTRY}

The construction projects based industry's ecosystem consists of multiple parties including owners, general contractors (GC), architects, engineers, subcontractors and material suppliers. The different organizational entities, i.e. each project participant, follow different business process and have different corporate goals to accomplish in the project. GCs are most likely the largest organizational entities with most critical financial stake in the success of the project, but all parties share significant financial concerns hinging on the positive outcome of all business transactions. Furthermore, the abundance of disintegrated information and its time-sensitiveness in the construction industry makes projects complex to manage. Reviewing components of Iecos, this particular industry poses a unique challenge because nonintegrated nature of multiple parties' business processes, complex pricing structure, non-integrated technologies on the project sites and varied labor force.

\section{CONCLUSION}

The current study provides a simplistic view of application selection criterion instead of existing TAM which has been extended to simple unmanageable number of variables.

Information provides an understanding of the current application space, both internal and external. Researchers and executives therefore can appreciate IECOS as a tool, and evaluate the ecosystem variables before spending millions of dollars in systems installation and upgrades, to automate back offices and extending its system footprint. Companies are currently attempting to snatch data in every conceivable way within existing business data availability from multiple sources.

The study contributes to developing an ecosystem of components present in adopting a new solution. The study provides a framework to identify critical components present in the acceptance process. The study also has broad implications in extending the scope of
TAM from adopting new solution perspective. Several researchers pointed out limitation of TAM's perceived usage as the primary criterion for success. The current study also extended to risk and external factors are criterion for success as well.

However the current theoretical proposition needs to be validated by expert feedback, surveys or case studies. The current authors are currently working on the survey design to validate the hypothesis presented in this paper. The ecosystem also needs to be validated in different industries including project based industries and validate the proposed IECOS

\section{REFERENCES}

1. Bagozzi, R.: The Legacy of the Technology Acceptance Model and a Proposal for a Paradigm Shift (Journal of the Association for Information Systems, Issue 4, Article 7.

2. Chung, BooYoung (2007):An analysis of success and failure factors for ERP systems in Engineering and Construction firms. PhD Thesis, University of Maryland, Project Management Program, University of Maryland, College, MD

3. Comrey and Lee's (1992): Higher-order exploratory factor analysis of the Reynolds Intellectual Assessment Scales with a referred sample: Journal of School Psychology Vol. 45, Issue 4, August 2007, Pages 439-456

4. D. Robey, J. W. Ross, and M.-C. Boudreau, "Learning to implement enterprise systems: An exploratory study of the dialectics of change," $J$. Manage. Inform. Syst., vol. 19, no. 1, 2002.

5. David Hosmer and Stanley Lemeshow: Applied Logistic Regression (Second Edition)

6. David L. Olson Evaluation of ERP outsourcing, Computers \& Operations Research 34 (2007) 37153724

7. Doz, Y., Santos, J. and Williamson, P., "From Global to Metanational". Harvard Business School Press: 2001, ISBN 0-87584870-2

8. Ekanayaka et al. Evaluating application service providers, Benchmarking: An International Journal, Vol 10, No 4, 2003, pp 343-354

9. Elena Karahanna et al. Reconceptualizing Compatibility beliefs in Technology Acceptance Research, MIS Quarterly, Vol 30, No 4, Dec - 2006 pp 781-804

10. Gad Ariav and Michael J. Ginzberg. Dss design: a systemic view of decision support.Communications of the ACM, 28(10):1045-1052, October 1985. 
11. Ghosh S, and Ghosh, S: Critical success factors evaluating IT infrastructure: IEEE Engineeering Management Conference, Singapore, 2003

12. Hall, C.A.S., Day, J.W. Jr, 1977. Systems and models: terms and basic principles. In: Hall, C.A.S., Day, J.W. Jr (Eds.), Ecosystem Modeling in Theory and Practice: An Introduction with Case Histories. Wiley, New York, pp. 6-36.

13. J Lu, CS Yu, C Liu, JE Yao: Technology acceptance model for wireless Internet Author(s): Internet Research, 2003

14. J. Michael Pearson and J.P. Shim. An empirical investigation into decision support systems capabilities: a proposed taxonomy. Information \& Management, 27(1):45-57, 1994.

15. Jack T. Hogue and Hugh J. Watson. An examination of decision-makers' utilization of decision support system output. Information \&' Management, 8(4):205-212, April 1985.

16. Jackson, Pamela J.: Modeling The Individual Technology Adoption Decision: A Synthesis of the Quantitative and Qualitative Literature, 2006: UNC Chatlotte, eScholar Academic Research, http://hdl.handle.net/2029/6

17. Jerry Cha-Jan Chang and William $\mathrm{R}$ King: Measuring the Performance of Information Systems: A Functional Scorecard: Journal of Management Information Systems: Summer 2005, Vol 22, No 1, pp 85-115

18. JH Wu, SC Wang - Information \& Management, 2005 - Elsevier "What drives mobile commerce? An empirical evaluation of the revised technology acceptance model".

19. Kwasi Amoako-Gyampah and A. F. Salam: An extension of the technology acceptance model in an ERP implementation environment: Information \& Management, Volume 41, Issue 6, July 2004, p. 731745

20. Lee, A.S. "Integrating Positivist and Interpretive Approaches to Organizational Research," Organization Science (2), 1991, pp. 342-365.

21. M. Hammer, "Up the ERP revolution," Information week, p. 186, Feb, 1999.

22. Maarten Celderman (1997): Task difficulty, task variability and satisfaction with Management support system: Vrije Universiteit Research Memorandum, 1997-53.

23. Mankins, M. C. and Steele, R. (2005) Turning Great Strategy into Great Performance, Harvard Business Review, Harvard Business School. 83(1), pp 64-72
24. More, E. "Information Systems: People Issues," Journal of Information Science (16:5), 1990, pp. 311-320.

25. Morris, M.G. and Dillon, A. "How User Perceptions Influence Software Use," IEEE Software (14:4), 1997, pp. 58-65.

26. Morrison, Donald F. (1990) Multivariate Statistical Methods. New York: McGraw-Hill.

27. Orlikowski, W.J. and Baroudi, J.J. "Studying Information Technology in Organizations: Research Approaches and Assumptions," Information Systems Research (2:1), 1991, pp. 1-26.

28. Ron Adner, Match Your nnovation Strategy to Your Innovation Ecosystem, HBR

29. Sharma and Yetton: The contingent effects of Training, Technical Complexity, and Task Interdependence on Successful Information Systems Implementation: MIS Quarterly Vol 31, No 2, pp 219-238

30. SL Zeger and KY Liang Longitudinal Data Analysis for Discrete and Continuous Outcomes, Biometrics, 1986 - JSTOR

31. Somers, T.M. and Nelson, K.L.: A taxonomy of players and activities across the ERP project life cycle: Information and Management, Vol 41(2004), pp 257-278

32. Tabachnick and Fidell : Computer-Assisted_Reseach and Design Analysis Allyn \& Bacon: (2001, page 588)

33. Tiwana, A and Mclean E.: Expertise Integration and Creativity in Information Systems Development, Journal of Management Information Systems / Summer 2005, Vol. 22, No. 1, pp. 13-43.

34. Venkatesh, V., and Davis, F. D. (2000). "A Theoretical Extension of the Technology Acceptance Model: Four Longitudinal Field Studies." Management Science, INFORMS, 46(2), 186-204.

35. VIDYANAND CHOUDHARY, Comparison of Software Quality Under Perpetual Licensing and Software as a Service, Journal of Management Information Systems / Fall 2007, Vol. 24, No. 2, pp. 141-165.

36. Wenhong Luo and Diane M. Strong A Framework for Evaluating ERP Implementation Choices, Ieee Transactions On Engineering Management, Vol. 51, No. 3, August 2004

37. Woods, J. A. and McCurley, C. J. (2004, Apr) Design Effects in Complex Sampling Designs Paper presented at the annual meeting of the The Midwest Political Science Association, Palmer House Hilton, Chicago, Illinois 2006-10-05 from http://www.allacademic.com/meta/p83109 inde 